\title{
Hubungan Pengetahuan dan Peran Keluarga dengan Perilaku Remaja Putri dalam Menjaga Kesehatan Reproduksi di SMP Negeri 1 Kuta Baro Aceh Besar
}

\author{
Relationship of Knowledge and Family Role with Adolescent Girls' \\ Behavior in Maintaining Reproductive Health in SMP Negeri 1 Kuta \\ Baro Aceh Besar
}

\author{
Chairanisa Anwar*1, Eva Rosdiana ${ }^{2}$, Ulfa Husna Dhirah ${ }^{3}$, Marniati $^{4}$ \\ Universitas Ubudiyah Indonesia, Jln. Alue Naga Desa Tibang, Kecamatan Syiah Kuala, Banda Aceh, Indonesia \\ *Correspoding Author : chaira.anwar@uui.ac.id
}

\begin{abstract}
Abstrak
Kesehatan reproduksi adalah keadaan kesejahteraan fisik, mental, dan sosial yang utuh dan bukan hanya tidak adanya penyakit dan kelemahan, dalam segala hal yang berhubungan dengan sistem reproduksi dan fungsi-fungsi serta proses-prosesnya. Fenomena popularitas kesehatan reproduksi remaja putri lebih banyak di bahas dan di teliti, sedangkan kesehatan reproduksi remaja pria kurang mendapat perhatian dari masyarakat dan remaja itu sendiri. Minimnya pengetahuan mengenai proses-proses reproduksi, pentingnya menjaga kebersihan alat reproduksi, dan dampak dari perilaku yang tidak bertanggung jawab menyebabkan sebagian remaja mengalami masalah-masalah seperti remaja kurang menyadari akan pentingnya menjaga kesehatan reproduksinyaTujuan penelitian ini untuk untuk mengetahui hubungan pengetahuan dan peran keluarga dengan perilaku remaja putri dalam menjaga kesehatan reproduksi di SMP Negeri 1 Kuta Baro Aceh Besar tahun 2020. Jenis penelitian bersifat analitik dengan desain cross sectional. Pengumpulan data telah dilaksanakan tanggal 24 Februari 2020 di SMP Negeri 1 Kuta Baro Aceh Besar. Jumlah populasi seluruh remaja putri kelas VII sampai IX di SMP Negeri 1 Kuta Baro Aceh Besar sebanyak 48 orang.Instrumen penelitian menggunakan kuesioner dan pengambilan data dengan cara wawancara. Analisis data meggunakan analisis univariat dan bivariat. Hasil analisis bivariat pengetahuan $(\mathrm{p}=0.008)$, peran keluarga $(\mathrm{p}=0.023)$. Kesimpulan ada pengaruh pengetahuan dan peran keluarga dengan perilaku remaja menjaga kesehatan reproduksi. Diharapkan kepada orangtua agar dapat melakukan peranannya dalam upaya perlindungan kesehatan reproduksi kepada anaknya dengan cara mengenalkan kesehatan reproduksi mulai dari kecil serta menanamkan nilai budi pekerti, sehingga anak dapat menunjukkan perilaku yang baikdalam pergaulan di dalam keluarga, sekolah, maupun masyarakat.
\end{abstract}

Kata Kunci : Perilaku menjaga kesehatan reproduksi, pengetahuan, peran keluarga 


\section{Abstract}

Reproductive health is a state of complete physical, mental and social well-being and not only the absence of disease and weakness, in all matters relating to the reproductive system and its functions and processes. The phenomenon of the popularity of adolescent girls' reproductive health is more discussed and researched, while the reproductive health of young men receives less attention from the community and adolescents themselves. The lack of knowledge about reproductive processes, the importance of maintaining cleanliness of the reproductive organs, and the impact of irresponsible behavior causes some adolescents to experience problems such as adolescents less aware of the importance of maintaining their reproductive health. adolescent girls in maintaining reproductive health in SMP Negeri 1 Kuta Baro Aceh Besar in 2020. This type of research is analytic with cross sectional design. Data collection was carried out on February 24, 2020 at SMP Bar 1 Kuta Baro Aceh Besar. The total population of all young women class VII to IX in SMP Negeri 1 Kuta Baro Aceh Besar was 48 people. The research instrument used a questionnaire and data collection by interview. Data analysis uses univariate and bivariate analysis. The results of the bivariate analysis of knowledge $(p=0.008)$, the role of the family $(p=0.023)$. The conclusion is the influence of knowledge and the role of families with adolescent behavior to maintain reproductive health. It is expected that parents can carry out their role in efforts to protect reproductive health of their children by introducing reproductive health from a small age and instilling the value of character, so that children can show good behavior in relationships in the family, school, and community.

Keywords: Behavior to maintain reproductive health, knowledge, family roles

\section{PENDAHULUAN}

Remaja merupakan masa peralihan dari masa anak-anak menuju masa dewasa. Jika dilihat dari segi kematangan biologis dan seksual, remaja sedang menunjukkan karakteristik seks sekunder sampai mencapai kematangan seks. Dilihat dari segi perkembangan kejiwaan, remaja sedang berkembang dari sifat anak-anak menjadi dewasa (Purwatiningsih, dkk 2010).

$$
\text { World Health Organization (WHO), remaja merupakan }
$$

penduduk dalam rentang usia 10-19 tahun. Sedangkan menurut Peraturan Mentri Kesehatan RI Nomor 25 tahun 2014, remaja adalah penduduk dalam rentang usia 10-18 tahun dan menurut Badan Kependudukan dan Keluarga Berencana (BKKBN) rentang usia remaja adalah 10-24 tahun dan belum menikah. Jumlah kelompok usia 10-19 tahun di Indonesia menurut sensus penduduk 2015 sebanyak 45,5 juta atau sekitar $20 \%$ dari jumlah penduduk. Kelompok remaja di dunia berjumlah 1,2 milyar atau $18 \%$ dari jumlah penduduk dunia (WHO, 2014).

Kesehatan reproduksi adalah keadaan kesejahteraan fisik, mental, dan sosial yang utuh dan bukan hanya tidak adanya penyakit dan kelemahan, dalam segala hal yang berhubungan dengan sistem reproduksi dan fungsi-fungsi serta proses-prosesnya. Fenomena 
Journal of Healthcare Technology and Medicine Vol. 6 No. 1 April 2020

Universitas Ubudiyah Indonesia

e-ISSN : 2615-109X

popularitas kesehatan reproduksi remaja putri lebih banyak di bahas dan di teliti, sedangkan kesehatan reproduksi remaja pria kurang mendapat perhatian dari masyarakat dan remaja itu sendiri.

Minimnya pengetahuan mengenai proses-proses reproduksi, pentingnya menjaga kebersihan alat reproduksi, dan dampak dari perilaku yang tidak bertanggung jawab menyebabkan sebagian remaja mengalami masalah-masalah seperti remaja kurang menyadari akan pentingnya menjaga kesehatan reproduksinya (Widyastuti, 2014).

Pada alat reproduksi yang tidak terjaga kebersihannya tentu sangat rentan terserang penyakit akibat jamur atau bakteri. Penyakit reproduksi juga dapat di sebabkan dari pola hidup yang tidak sehat pada masa remaja yang dapat berpengaruh pada fertilitas remaja di masa reproduksi (Romauli dan Vindari, 2009).

Salah satu masalah kesehatan reproduksi remaja khususnya wanita
yang sering dikeluhkan adalah keputihan. Sering kali keputihan dapat mengganggu hingga menyebabkan ketidaknyamanan dalam aktifitas sehari-hari. Keputihan dapat berupa fisiologis (normal) dan patologis (tidak normal) (Agustini dalam Deissy, 2013). Keputihan adalah semacam slim yang keluar terlalu banyak, warnanya putih seperti sagu kental dan agak kekuning-kuningan. Jika slime atau lendir ini tidak terlalu banyak, tidak menjadi persoalan (Sasmiyanti \& Handayani, 2008). Keputihan (Fluor albus) merupakan salah satu tanda dan gejala penyakit organ reproduksi wanita, di daerah alat genitalia eksternal bermuara saluran kencing dan saluran pembuangan sisa-sisa pencernaan yang disebut anus. Apabila tidak dibersihkan secara sempurna akan ditemukan berbagai bakteri, jamur dan parasit, akan menjalar ke sekitar organ genitalia yang dapat menyebabkan infeksi dengan gejala keputihan.

\section{METODE PENELITIAN}

Penelitian ini menggunakan jenis penelitian yang bersifat analitik dengan desain crosssectional. Populasi dalam penelitian ini adalah seluruh remaja putri kelas VII sampai IX di SMP Negeri 1 Kuta Baro Aceh Besar sebanyak 48 orang. Teknik pengambilan sampel dalam penelitian ini adalah Purposive Sampling yaitu pengambilan sampel berdasarkan kriteria yang telah ditentukan oleh peneliti. Instrumen penelitian ini menggunakan kuesioner dan pengumpulan data dengan cara wawancara. Pengumpulan telah dilaksanakan pada 24 Februari 2020 di SMP Negeri 1 Kuta Baro Aceh Besar. Pengolahan data menggunakan 
Journal of Healthcare Technology and Medicine Vol. 6 No. 1 April 2020

Universitas Ubudiyah Indonesia

e-ISSN : 2615-109X

computer melalui proses editing, coding, transferring dan tabulating. Analisis data dengan dua data yaitu analisis univariat dan bivariat.

\section{HASIL PENELITIAN}

Tabel. 1

Distribusi Frekuensi Perilaku Remaja dalam Menjaga Kesehatan Reproduksi di SMP Negeri 1 Kuta Baro Aceh Besar tahun 2020

\begin{tabular}{|c|c|c|c|}
\hline No & $\begin{array}{c}\text { Perilaku Remaja dalam Menjaga } \\
\text { Kesehatan Reproduksi }\end{array}$ & Frekuensi (f) & Persentase (\%) \\
\hline 1 & Negatif & 27 & 56.3 \\
\hline 2 & Positif & 21 & 43.8 \\
\hline \multicolumn{2}{|r|}{ Total } & 48 & 100.0 \\
\hline
\end{tabular}

Berdasarkan Tabel 1 diatas dapat dilihat bahwa perilaku remaja dalam menjaga kesehatan reproduksi dominasi oleh perilaku negatif yaitu sebanyak 27 orang (56.3\%), sedangkan perilaku positif sebanyak 21 orang $(43.8 \%)$.

Tabel. 2

Distribusi Frekuensi Pengetahuan Remaja tentang Kesehatan Reproduksi di SMP Negeri 1 Kuta Baro Aceh Besar tahun 2020

\begin{tabular}{llccc}
\hline No & & Pengetahuan Remaja & Frekuensi (f) & Persentase (\%) \\
\hline 1 & Kurang & & 25 & 52.1 \\
2 & Baik & & 23 & 47.9 \\
& & & \\
\hline \multicolumn{2}{r}{ Total } & $\mathbf{4 8}$ & $\mathbf{1 0 0 . 0}$ \\
\hline
\end{tabular}

Berdasarkan Tabel 2 dapat dilihat bahwa perilaku negatif remaja dalam menjaga kesehatan reproduksi didominasi oleh pengetahuan yang kurang yaitu 25 orang (52.1\%), sedangkan pengetahuan baik hanya 23 orang $(47.9 \%)$.

Tabel 3

Distribusi Frekuensi Peran Keluarga di SMP Negeri 1 Kuta Baro Aceh Besar tahun 2020

\begin{tabular}{llcc}
\hline No & \multicolumn{1}{c}{ Peran Keluarga } & Frekuensi (f) & Persentase (\%) \\
\hline 1 & Tidak Berperan & 25 & 52.1 \\
2 & Berperan & 23 & 47.9 \\
& & & \\
\hline \multicolumn{2}{r}{ Total } & $\mathbf{4 8}$ & $\mathbf{1 0 0 . 0}$ \\
\hline
\end{tabular}

Berdasarkan Tabel 3 dapat dilihat bahwa peran keluarga dalam memberikan informasi kepada remaja didominasi oleh keluarga yang tidak berperan yaitu 25 orang $(52.1 \%)$, sedangkan keluarga yang berperan hanya 23 orang $(47.9 \%)$. 
Tabel 4

Hasil Analisis Bivariat Hubungan Pengetahuan Remaja dan Peran Keluarga dengan Perilaku Menjaga Kesehatan Reproduksi pada Remaja Putri di SMP

Negeri 1 Kuta Baro Aceh Besar tahun 2020

\begin{tabular}{lcccccccc}
\hline \multirow{2}{*}{ Variabel Independen } & \multicolumn{3}{c}{ Perilaku Menjaga Kespro } & \multicolumn{2}{c}{ Total } & \multirow{2}{*}{ P- Value } \\
\cline { 2 - 6 } & Negatif & \% & Positif & $\%$ & f & \% & \\
\hline $\begin{array}{l}\text { Pengetahuan Remaja } \\
\quad \text { 1. Kurang }\end{array}$ & 19 & 76.0 & 6 & 24.0 & 25 & 100 & \\
$\quad$ 2. Baik & 8 & 34.8 & 15 & 65.2 & 23 & 100 & 0.008 \\
\hline $\begin{array}{l}\text { Peran Keluarga } \\
\quad \text { 1. Berperan }\end{array}$ & 10 & 40.0 & 15 & 60.0 & 25 & 100 & \\
$\quad$ 2. Tidak Berperan & 17 & 73.9 & 6 & 26.1 & 23 & 100 & 0.023 \\
\hline
\end{tabular}

Sumber : Data primer (diolah tahun 2020)

\section{PEMBAHASAN}

\section{Pengetahuan}

Pengetahuan atau Kognitif merupakan domain yang terpenting dalam tindakan seseorang. Sehingga sangat diperlukan sekali untuk meningkatkan pengetahuan remaja di SMP Negeri 1 Kuta Baro Aceh Besar, banyak cara yang dapat dilakukan untuk meningkatkan pengetahuan pada remaja mulai dari pendidikan dini dari orang tua dan memberikan kegiatan penyuluhan, sehingga remaja akan lebih memahami dan mampu mengaplikasikan teori yang didapatkan dengan kenyataan yang ada. Dalam masa perubahan seperti yang dialami remaja banyak hal yang terkadang diabaikan karena adanya anggapan bahwa masalah itu merupakan masalah kecil dan tidak perlu disampaikan. Padahal masalah sekecil apapun, informasi sekecil apapun itu merupakan hal yang besar bagi masa perkembangan remaja.

Remaja putri rentan terkena infeksi organ reproduksi. Hal ini terjadi karena kurangnya perilaku dalam merawat kebersihan diri terutama saat mengalami menstruasi. Remaja putri memiliki tingkat perhatian yang rendah terkait kesehatan reproduksi. Menurut hasil penelitian Wulandari tahun 2012, didapatkan bahwa pengetahun yang diterima remaja putri berusia 13 hingga 16 tahun tentang perawatan alat reproduksi eksternal ketika menstruasi sebagian besar adalah cukup, yaitu 62 persen. Selain itu, perilaku dalam melakukan perawatan terhadap organ reproduksi eksternal yang mayoritas dalam frekuensi cukup sejumlah 48 persen. Permasalahan ini disebabkan oleh pendidikan yang tergolong 
Journal of Healthcare Technology and Medicine Vol. 6 No. 1 April 2020

Universitas Ubudiyah Indonesia

e-ISSN : 2615-109X

rendah dan memiliki usia relatif muda diasumsikan tidak memiliki faktor pemungkin untuk terkena suatu penyakit yang dapat menyerang organ reproduksi Sari, 2012). Sementara itu, Lely tahun 2012 mengungkapkan peningkatan kejadian infeksi pada organ reproduksi dapat dipengaruhi oleh zaman globalisasi diwujudkan dengan lebatnya aliran informasi yang deras dan cepat.

Berdasarkan data yang dihimpun dari Badan Pusat Statistik dan Badan Perencanaan Pembangunan Nasional pada tahun 2010, 63 juta remaja di Negara Indonesia berisiko melakukan perilaku yang tidak sehat. Misalnya, kurangnya tindakan merawat kebersihan organ reproduksi. Angka insidensi penyakit infeksi yang terjadi pada saluran reproduksi remaja (10-18 tahun), yaitu 35-42 persen serta dewasa muda (18-22 tahun) sebesar 27-33 persen. Rahmatika (2010) dalam penelitiannya mengungkapkan bahwa faktor pemicu kasus ISR antara lain imunitas yang rendah sejumlah 10 persen, perilaku kurang dalam merawat hygiene ketika menstruasi sejumlah 30 persen, lingkungan buruk dan tata cara dalam penggunaan pembalut yang kurang tepat ketika menstuasi sejumlah 50 persen. Pemaparan tersebut juga diperkuat dari hasil penelitian yang dilakukan Ariyani (2009) terkait dengan biopsikososial hygiene saat menstruasi pada siswi SMP di ibukota Jakarta menekankan bahwa remaja putri yang mempunyai perilaku baik dalam perawatan hygiene genitalia ketika mendapati dirinya menstruasi hanya 17,4 persen. Sisanya yaitu sejumlah 82,6 persen memiliki perilaku yang kurang dalam menjaga kebersihan alat genitalia ketika menstruasi.

Pengetahuan yang diberikan memiliki tujuan, yaitu penambahan informasi mengenai menstruasi. Materi tersebut perlu diutarakan kepada kelompok remaja putri. Sukarni tahun 2013, menjelaskan pengetahuan terkait menstruasi sangat dibutuhkan oleh para remaja putri. Konsekuensi yang muncul dari rendahnya pengetahuan ialah kurang mendapatkan informasi terkait personal hygiene terutama pada saat mengalami mentruasi. Tingkat pendidikan orang tua yang rendah dan kurangnya pengetahuan remaja tentang menstruasi sering dikira bahwa kesehatan pada reproduksi merupakan suatu perbincangan paling tabu untuk diulas dengan detail dan mendalam. Pernyataan ini dipertegas oleh penelitain Kurniawati, dkk (2012) bahwa orang tua sangat sentiment dalam membahas reproduksi kepada anaknya. Kesehatan reproduksi dianggap tidak layak untuk dilontarkan karena terkait rahasia setiap individu merasa tidak nyaman apabila disuruh membahas hal tersebut. Pendidikan kesehatan seputaran reproduksi semestinya sudah diberikan kepada seorang remaja, bahkan harus disampaikan sedini mungkin. Hal ini dilakukan karena 
Journal of Healthcare Technology and Medicine Vol. 6 No. 1 April 2020

Universitas Ubudiyah Indonesia

e-ISSN : 2615-109X

informasi yang telah diperoleh sejak kecil, kelak akan bermanfaat untuk disimpan dan dipergunakan sebagai suatu bekal saat dewasa nanti.

Hal ini dibuktikan dengan penelitian yang dilakukan oleh Indriyani Tahun 2009 tentang Hubungan Tingkat Pengetahuan Kesehatan Reproduksi Dengan Perilaku Personal Hygiene Pada Remaja Putri di SMAN 5 Surakarta yang menunjukkan bahwa Pengetahuan kesehatan reproduksi pada remaja yang mempunyai nilai diatas rata - rata $($ mean $=27,56)$ yaitu sebanyak 128 responden (66,67\%). Hal ini menunjukkan bahwa sebagian besar remaja mempunyai pengetahuan yang baik tentang kesehatan reproduksi karena Institusi tersebut bekerjasama dengan tenaga kesehatan untuk memberikan penyuluhan tentang kesehatan reproduksi pada siswa yang baru masuk kelas X. Pada mata pelajaran Bimbingan dan Konseling serta Biologi dipelajari tentang kesehatan reproduksi. Siswi di SMAN 5 Surakarta juga mendapatkan informasi tentang kesehatan reproduksi dan premenstrual syndrome (PMS) yang diperoleh dari berbagai sumber informasi, antara lain media cetak (koran, majalah, poster), media elektronik (televisi, radio), media internet, keluarga, teman dan lain - lain (penyuluhan, seminar). Sumber informasi tentang kesehatan reproduksi dan premenstrual syndrome (PMS) yang paling banyak diperoleh dari media cetak (koran, majalah, poster).

Asumsi peneliti, pengetahuan remaja putri yang dinilai baik akan mempengaruhi sikap sehingga bentuk perilaku untuk berusaha menjaga kebersihan genitalia akan positif. Perilaku memiliki pengertian, yaitu sebuah respons untuk melakukan suatu tindakan tertentu. Perilaku positif ini dipengaruhi adanya pendidikan mengenai kesehatan terutama sistem reproduksi yang diperhatikan orang tua maupun remaja itu sendiri. Orang tua mempunyai andil yang besar untuk menanamkan pemahaman terkait kesehatan reproduksi terhadap anak. Sehingga dengan pengetahuan yang baik terjagalah kebersihan alat reproduksi sehingga angka kejadian kasus infeksi genitalia pada remaja berkurang, sehingga tidak menimbulkan masalah infertilitas pada usia reproduksi.

\section{Peran Keluarga}

Hasil uji statistik dengan menggunakan uji chi-square menunjukkan perbedaan presentase tersebut bermakna yaitu dengan nilai $\mathrm{P}=0.023$ artinya ada hubungan bermakna antara peran keluarga dengan perilaku remaja dalam menjaga kesehatan reproduksinya, terlihat bahwa responden yang berperilaku positif dalam menjaga kesehatan reproduksinya lebih banyak dijumpai pada remaja putri yang keluarganya berperan $(60.0 \%)$ dari pada remaja putri yang keluarganya tidak berperan $(26.1 \%)$. 
Journal of Healthcare Technology and Medicine Vol. 6 No. 1 April 2020

Universitas Ubudiyah Indonesia

e-ISSN : 2615-109X

Remaja mempunyai masalah kesehatan reproduksi yang dapat berubah menurut siklus kehidupan, serta dipengaruhi oleh budaya dan praktek-praktek medis yang berkaitan dengan kesehatan reproduksi segera setelah mereka lahir. Ketika anak mencapai masa pubertas, mereka mulai merasakan perubahan fisik, termasuk perubahan suara, munculnya alat kelamin sekunder, serta meningkatnya perkembangan jaringan otot. Perubahanperubahan fisik ini sering kali diikuti dengan perubahan emosional dan perilaku, termasuk perkembangan perasaan seksual, belajar tentang hal-hal seksual, dan pertanyaanpertanyaan seputar isu seksualitas. Pengalaman dan respon anak terhadap perubahan ini membentuk tingkat yang lebih tinggi terhadap gender dan antisipasi terhadap budayanya.

Peran orang tua adalah seperangkat tingkah laku dua orang ayah- ibu dalam bekerja sama dan bertanggung jawab berdasarkan keturunannya sebagai tokoh panutan anak semenjak terbentuknya pembuahan atau zigot secara konsisten terhadap stimulus tertentu baik berupa bentuk tubuh maupun sikap moral dan spiritual serta emosional anak yang mandiri.

Lingkungan keluarga menjadi satu faktor yang bisa mempengaruhi para kalangan remaja agar terhindar dari pengaruh pergaulan bebas. Peranan orang tua menjadi salah satu filter agar anak remajanya tak terjerumus dalam pergaulan yang mengarah pada perilaku seks bebas. Hubungan orangtua yang harmonis akan menumbuhkan kehidupan emosional yang optimal terhadap perkembangan kepribadian anak sebaliknya. Orang tua yang sering bertengkar akan menghambat komunikasi dalam keluarga, dan anak akan "melarikan diri“" dari keluarga. Keluarga yang tidak lengkap misalnya karena perceraian, kematian, dan keluarga dengan keadaan ekonomi yang kurang, dapat mempengaruhi perkembangan jiwa anak menurut Rohmahwati (2008).

Sebagai orang tua bentuk kasih sayang yang diberikan tidak hanya memberikan pendidikan dan kepercayaan kepada anaknya tetapi juga penting untuk selalu mengontrol perkembangan anaknya, dan sebagai orang tua juga dapat menepatkan diri sebagai teman kepada anaknya agar anak lebih terbuka dengan orang tua dan akan merasa nyaman untuk menceritakan apa yang selalu terjadi pada dirinya dengan begitu orang tua akan dapat dengan mudah mengontrol perkembangan anaknya serta mengajarkan tentang pentingnya melindungi kesehatan reproduksi. Bila setiap orang tua, keluarga, dan pemerintah masingmasing memberikan perhatian yang cukup pada remaja dan turut serta mendukung terpeliharanya nilai-nilai moral dan etika, maka akan tercipta suasana sehat bagi kehidupan remaja. 
Journal of Healthcare Technology and Medicine Vol. 6 No. 1 April 2020

Universitas Ubudiyah Indonesia

e-ISSN : 2615-109X

Upaya Perlindungan Kesehatan Reproduksi merupakan suatu hal yang harus bersifat kooperatif dari berbagai aspek seperti diri sendiri, pihak orang tua, sekolah dan lingkungan masyarakat yang harus diimbangi oleh norma agama dan sosial, untuk melindungi kesehatan reproduksi pada anak. Upaya perlindungan kesehatan reproduksi dapat dilakukan orang tua melalui cara sebagai berikut: (1) Penanaman Nilai Budi Pekerti, yang mengandung nilai keagamaan, kesusilaan dan kepribadian. (2) Memfasilitasi perkembangan anak yaitu : memfasilitasi anak untuk berinterkasi dalam kelompok sebaya; menganjurkan anak mengikuti organisasi yang mempunyai kegiatan positif; orang tua berperan sebagai teman berbagi cerita bagi anak; orang tua berperan sebagai contoh peran bagi anak dalam melakukan interaksi sosial yang baik; memberikan lingkungan yang nyaman bagi anak dalam melakukan aktivitasnya bersama kelompoknya; membimbing remaja dalam menentukan rencana masa depannya. (3) Mengenalkan perlindungan kesehatan reproduksi dengan cara sebagai berikut : Mengubah cara berpikir anak, bahwa makna pendidikan perlindungan kesehatan reproduksi itu sangat luas, tidak hanya berkisar masalah jenis kelamin dan hubungan seksual, tapi didalamnya ada perkembangan manusia, hubungan antar manusia, kemampuan personal (yang didalamnya terdapat tentang nilai, komunikasi, negosiasi dan pengambilan keputusan, perilaku seksual, kesehatan seksual, pencegahan infeksi menular, serta budaya dan masyarakat. Mengajarkan tentang kesehatan reproduksi sejak dini. Gunakan istilah yang tepat sesuai dengan usianya, misalnya anak yang beranjak remaja, maka gunkanlah bahasa yang biasa digunakan remaja, sehingga anak tidak sungkan untuk menanggapi pembicaraan anda.

Asumsi peneliti, peran orang tua dalam mengikuti perkembangan anak, mulai dari tahap anak menjadi remaja harus sangatlah aktif, terutama ibu. Anak harus dibekali pengetahuan yang baik untuk menjalankan fungsi reproduksinya sehingga anak dapat bertanggung jawab terhadap dirinya. Seorang anak mesti bersikap terbuka kepada orangtua akan semua hal yang berkaitan dengan reproduksinya, juga orang tua harus memberikan informasi secara jelas atas keingintahuan anak. Masalah reproduksi pada remaja sebagian besar dimulai ketika orangtua menganggap tabu membicarakan hal seputar cara membersihkan organ reproduksi anak, dimana anak tidak mendapatkan informasi bagaimana merawat organ reproduksi, seperti diketahui menarche normalnya diperoleh saat remaja usia sekolah SMP, tentu usia yang sangat muda dan sangat perlu bimbingan orangtua tentag cara menggunakan pembalut, cara membuang pembalut dan 
Journal of Healthcare Technology and Medicine Vol. 6 No. 1 April 2020

Universitas Ubudiyah Indonesia

e-ISSN : 2615-109X

cara membersihkan alat genitalianya. Sehingga diharapkan tidak lagi terjadi masalah seputar infeksi pada organ genitalia remaja.

\section{SIMPULAN}

Berdasarkan hasil penelitian dapat disimpulkan bahwa ada hubungan pengetahuan ( $\mathrm{p}=$ 0.008) dan peran keluarga $(\mathrm{p}=0.023)$ dengan perilaku remaja dalam menjaga kesehatan reproduksi di SMP Negeri 1 Kuta Baro Aceh Besar.

\section{SARAN}

Diharapkan kepada orang tua dapat melakukan peranannya dalam upaya perlindungan kesehatan reproduksi kepada anaknya dengan cara mengenalkan kesehatan reproduksi mulai dari kecil serta menanamkan nilai budi pekerti, sehingga anak dapat menunjukkan perilaku yang baik dalam pergaulan di dalam keluarga, sekolah, maupun masyarakat.

\section{UCAPAN TERIMA KASIH}

Ucapan terima kasih kepada Universitas Ubudiyah Indonesia yang telah memberikan dukungan finansial dalam penelitian ini dan ucapan terima kasih kepada Kepala Sekolah SMP Negeri 1 Kuta Baro yang telah memberikan izin penelitian dan para responden yang telah membantu peneliti dalam memberikan informasi yang dibutuhkan peneliti.

\section{DAFTAR PUSTAKA}

Agustini, Fauziah, 2010. Manajemen Sumber Daya Manusia Lanjutan. Medan: Madenatera.

BKKBN, 2011. Profil Hasil Pendataan Keluarga Tahun 2011. Jakarta: Badan Kependudukan dan Keluarga Berencana Nasional Direktorat Pelaporan dan Statistik.

Hendra, AW. 2008. Faktor Faktor Yang Mempengaruhi Pengetahuan. Diakses $\begin{array}{llll}\text { tanggal } & 31 & \text { Desember }\end{array}$ http://www.ajangberkarya.Wordpress.com/2008/06/07/konsep pengetahuan.htm.

Imron, A. 2011. Manajemen Peserta Didik Berbasis Sekolah. Jakarta: Bumi Aksara.

Mappiare, Andi. __. Psikologi Remaja. Surabaya: Usaha Nasional.

Notoatmodjo, S. 2010. Metodologi Penelitian Kesehatan. Jakarta : Rineka Cipta.

Nugroho, Taufan. 2010. Buku Ajar Ginekologi. Yogyakarta: Nuha Medika.

Purwaningsih, dkk. 2010. Asuhan Keperawatan Maternitas. Yogyakarta : Nuha Medica.

Romauli, S. Vindari, A.M. (2009). Kesehatan Reproduksi buat Mahasiswi Kebidanan. Yogyakarta: Nuha Medika.

Widyastuti, Y., dkk. 2014. Kesehatan Reproduksi. Yogyakarta: Fitrimaya. 
Journal of Healthcare Technology and Medicine Vol. 6 No. 1 April 2020

Universitas Ubudiyah Indonesia

e-ISSN : 2615-109X

Winerungan, Oktaviane Lidya. 2013. Sosialisasi Perpajakan, Pelayanan Fiskus dan Sanksi Perpajakan Terhadap Kepatuhan WPOP di KPP Manado dan KPP Bitung. Jurnal EMBA. Vol.1 No.3 ISSN: 960-97. 